JURNAL SOSIAL-EKONOMI PERTANIAN DAN AGRIBISNIS

JOURNAL ON SOCIO-ECONOMICS OF AGRICULTURE AND AGRIBUSINESS

\title{
FAKTOR YANG MEMPENGARUHI RESPON PETANI GARAM TENTANG SISTEM RESI GUDANG DI DESA RACI KECAMATAN BATANGAN
}

\author{
Anggun Novita Sari dan Yuliawati \\ Fakultas Pertanian dan Bisnis Universitas Kristen Satya Wacana, \\ Salatiga, Jawa Tengah \\ E-mail: anggunans@gmail.com,yuliawati@staff.uksw.edu
}

HP: 085641601570

\begin{abstract}
ABSTRAK
Penelitian ini bertujuan untuk mendiskripsikan pelaksanaan Sistem Resi Gudang dan mencari faktor-faktor apa saja yang mempengaruhi respon petani garam terhadap Sistem Resi Gudang. Penelitian dilaksanakan pada bulan Juni 2018 sampai dengan Juli 2018 di Desa raci Kecamatan Batangan. Desa Raci dipilih secara sengaja (purposive) sebagai lokasi penelitian atas pertimbangan bahwa di lokasi tersebut terdapat gudang penyimpanan yang menggunakan Sistem Resi Gudang. Teknik pengambilan sampel yang digunakan adalah probability sampling dengan metode simple random sampling dan diambil 70 orang sebagai responden penelitian. Sumber data menggunakan data primer yang diperoleh dari kuesioner dan data sekunder yang diperoleh dari instansi terkait seperti BPS dan Koperasi Mutiara Laut Mandiri (MLM). Teknik analisis data menggunakan regresi linear berganda menggunakan software EViews 9.0. Hasil yang diperoleh menunjukkan bahwa di Desa Raci hanya ada satu petani garam yang memanfaatkan Sistem Resi Gudang dan faktor yang mempengaruhi respon petani garam tentang Sistem Resi Gudang adalah tingkat pendidikan, persepsi, dan peran Penyuluh Pertanian Lapangan sedangan faktor yang tidak berpengaruh adalah umur, luas lahan, dan motivasi.
\end{abstract}

Kata Kunci: Petani, Garam dan Sistem Resi Gudang

\section{FACTORS AFFECTING SALT FARMER RESPONSE WAREHOUSE RECEIPT SYSTEM IN RACI VILLAGE BATANGAN DISTRICT}

\section{ABSTRACT}

This study aims to describe the flow of implementation of the Warehouse Receipt System and find out the factors that influence the response of salt farmers to the Warehouse Receipt System. This research was conducted from June to July 2018 in Raci Village, Batangan district. Raci Village was chosen purposively as the location of the study taking into account that the storage location was inaugurated using Warehouse Receipt System. The sampling technique used was probability sampling 
with simple random sampling method and 70 respondents were taken. The data source used was primary data obtained from questionnaires and secondary data obtained from related institution such as BPS and Mutiara Laut Mandiri Coorperattive $(M L M)$ as the warehouse manager. The data analysis techniques used is multiple linear regression using EViews 9.0 software. The result of the study shows that in Raci Village there was only one salt farmer that utilizes the Warehouse Receipt System and the factors that influence of salt farmers to the Warehouse Receipt System are the level of education, perception, and role field agricultural extension while the factors that did not influence were age, land area, and motivation.

Keywords: Farmers, Salt and Warehouse Receipt System

\section{PENDAHULUAN}

Garam adalah salah satu komoditas strategis karena termasuk ke dalam sembilan bahan pokok atau sering disebut dengan sembako. Indonesia merupakan negara maritim beriklim tropis sehingga sangat mungkin Indonesia menjadi negara produsen garam namun produksi garam nasional tidak sebanding dengan kebutuhan garam dalam negeri sehingga Indonesia harus mengimpor garam dari beberapa negara.

Produksi garam nasional hingga saat ini hanya mampu memenuhi kebutuhan garam dalam negeri dari segi konsumsi saja, sedangkan untuk kebutuhan garam dari segi industri Indonesia masih harus melakukan impor.

Tabel 1. Neraca Garam Nasional Tahun 2011 - 2014 (dalam Ton)

\begin{tabular}{|c|c|c|c|c|c|}
\hline \multirow[b]{2}{*}{ No } & \multirow{2}{*}{ Uraian } & \multicolumn{3}{|c|}{ Tahun } & \multirow{2}{*}{$\begin{array}{c}\text { Tren }(\%) \\
2013-2014\end{array}$} \\
\hline & & 2012 & 2013 & 2014 & \\
\hline \multirow[t]{8}{*}{1} & Kebutuhan & 3.270 .086 & $\begin{array}{r}3.573 .95 \\
4\end{array}$ & 3.611 .990 & 1,06 \\
\hline & Garam Konsumsi & 1.466 .336 & $\begin{array}{r}1.546 .45 \\
4\end{array}$ & 1.483 .115 & $-4,10$ \\
\hline & a. Rumah Tangga & 732.645 & 746.454 & 551.390 & $-31,49$ \\
\hline & b. Industri Aneka Pangan & 282.000 & 300.000 & 446.725 & 48,91 \\
\hline & c. Industri Pengasinan Ikan & 451.691 & 500.000 & 525.000 & 5,00 \\
\hline & Garam Industri & 1.803 .750 & $\begin{array}{r}2.027 .50 \\
0\end{array}$ & $\begin{array}{r}2.128 .87 \\
5\end{array}$ & 5,00 \\
\hline & a. Industri CAP dan Farmasi & 1.601 .000 & 1.822 .500 & 1.913 .625 & 5,00 \\
\hline & $\begin{array}{l}\text { b. Industri Non CAP (Kulit, Tekstil, } \\
\text { Sabun, Perminyakan, dsb) }\end{array}$ & 202.750 & 205.000 & 215.250 & 5,00 \\
\hline \multirow[t]{2}{*}{2} & Produksi & 2.071 .601 & $\begin{array}{r}1.087 .71 \\
5\end{array}$ & $\begin{array}{r}2.192 .16 \\
8\end{array}$ & 101,54 \\
\hline & $\begin{array}{l}\text { i. PT. Garam (Persero) } \\
\text { ii. Garam Rakyat }\end{array}$ & $\begin{array}{r}307.348 \\
1.764 .253\end{array}$ & $\begin{array}{l}156.829 \\
930.886\end{array}$ & $\begin{array}{r}315.000 \\
1.877 .168\end{array}$ & $\begin{array}{l}100,86 \\
101,65\end{array}$ \\
\hline \multirow[t]{3}{*}{3} & Impor & 2.314 .844 & $\begin{array}{r}2.020 .93 \\
3\end{array}$ & 2.251 .577 & 11,41 \\
\hline & i. Garam Konsumsi & 495.073 & 277.475 & 473.133 & 70,51 \\
\hline & $\begin{array}{l}\text { ii. Garam Industri CAP dan non } \\
\text { CAP }\end{array}$ & 1.819 .771 & 1.743 .458 & 1.778 .444 & 2,01 \\
\hline 4 & Ekspor & 2.624 & 2.849 & 2.166 & $-23,97$ \\
\hline
\end{tabular}


Dari tabel 1 dapat diketahui bahwa kebutuhan garam terdiri dari dua jenis yaitu garam konsumsi dan garam industri. Kebutuhan total garam pada tahun 2013-2014 mengalami kenaikan sebanyak 1,06\%. Pada produksi garam juga mengalami kenaikan sebesar 101,54\%. Import garam mengalami kenaikan sebesar $11,41 \%$. Meskipun kebutuhan garam nasional masih dipenuhi dari impor, namun Indonesia masih melakukan ekspor garam meskipun dalam jumlah yang kecil. Pada tahun 2013-2014 ekspor garam Indonesia mengalami penurunan sebanyak -23,97\%.

Gudang Garam Nasional (GGN) yang dibangun pemerintah dengan mekanisme tunda jual akan membantu petani garam untuk menstabilkan harga komoditas ketika sedang terjadi panen raya. Tahun 2006, DPR RI dengan inisiasi pemerintah telah mengesahkan UU No. 9 tahun 2006 tentang Sistem Resi Gudang (SRG) yang kemudian diamandemen dengan UU No. 9 tahun 2011. Pada pasal 1 ayat 1 dalam UU No. 9 tahun 2011 menyatakan bahwa SRG adalah kegiatan yang berkaitan dengan penerbitan, pengalihan, penjaminan, dan penyelesaian transaksi resi gudang. Pada awal tahun 2017 pemerintah mulai membangun gudang dengan SRG untuk komoditi garam di berbagai daerah salah satunya adalah di Desa Raci Kecamatan Batangan dengan kapasitas penyimpanan 2 ton. Pada kenyataannya masih banyak petani garam yang belum pernah menyimpan hasil panen di dalam gudang. Dalam kurun satu tahun, gudang baru menerbitkan satu resi saja. Menurut penelitian Nugraha (2014) terdapat beberapa faktor yang mempengaruhi respon petani te ntang SRG yaitu umur, tingkat pendidikan, luas lahan garapan, motivasi, persepsi, peran PPL dan status kepemilikan lahan. Sesuai dengan penelitian Nugraha (2014) yang menjelaskan bahwa di Bantul, sebagian besar kelompok tani belum menerapkan SRG karena kurangnya pemahaman tentang SRG, persyaratan yang cukup sulit dan beban biaya simpan, angkut, bongkar, muat dan pengeringan.

Garam merupakan komoditas baru yang masuk dalam komoditas yang dapat diresigudangkan sehingga penelitian mengenai SRG untuk komoditas garam masih jarang. Penelitian ini dilaksanakan karena selama ini penelitian tentang SRG lebih banyak dilakukan untuk komoditas pangan seperti padi dan jagung.

Penelitian ini bertujuan untuk mengetahui: (1) Gambaran pelaksanaan SRG di Desa Raci Kecamatan Batangan, (2) Faktorfaktor yang mempengaruhi respon petani garam tentang SRG.

\section{METODE}

Penelitian dilaksanakan di Desa Raci Kecamatan Batangan Kabupaten Pati. Desa Raci dipilih secara sengaja (purposive method) dengan pertimbangan bahwa di Desa Raci baru diresmikan gudang garam dengan menggunakan SRG. Metode penelitian yang digunakan adalah deskriptif kuantitaif. Penelitian dimulai pada bulan Juni 2018 sampai dengan Juli 2018.

Metode pengambilan sampel yang digunakan adalah probability sampling dengan menggunakan simple random sampling. Simple random sampling adalah teknik pengambilan 
sampel dari suatu populasi yang dilakukan secara acak tanpa memperdulikan strata (Sugiyono, 2011). Pengambilan jumlah anggota sampel mengacu pada pernyataan Roscoe dalam Sugiyono (2006) mengatakan bahwa apabila penelitian akan melakukan analisis multivariate (kolerasi atau regresi ganda) maka anggota sampel yang diambil minimal berjumlah 10 kali dari jumlah variabel yang diteliti. Variabel yang diteliti berjumlah tujuh variabel yaitu satu variabel terikat dan enam variabel bebas sehingga didapat 70 responden. Enam variabel bebas yang diteliti adalah umur (X1), tingkat pendidikan (X2), luas lahan (X3), motivasi (X4), persepsi (X5), peran PPL (X6)

sedangkan variabel terikatnya adalah respon petani garam (Y).

Jenis data yang digunakan unutk penelitian adalah data primer yaitu data yang diperoleh dari hasil wawancara dengan menggunakan instumen penelitian berupa kuesioner dan data sekunder yaitu data yang diperoleh dari instansi terkait seperti BPS dan Koperasi Mutiara Laut Mandiri (MLM) selaku pihak pengelola gudang.

Uji validitas dan reliabilitas dilakukan terhadap instrumen penelitian (kuesioner) untuk variabel respon petani garam (Y), motivasi (X4), persepsi (X5), dan peran PPL (X6). Berikut adalah diagram alur metode yang dilaksanakan dalam penelitian ini:

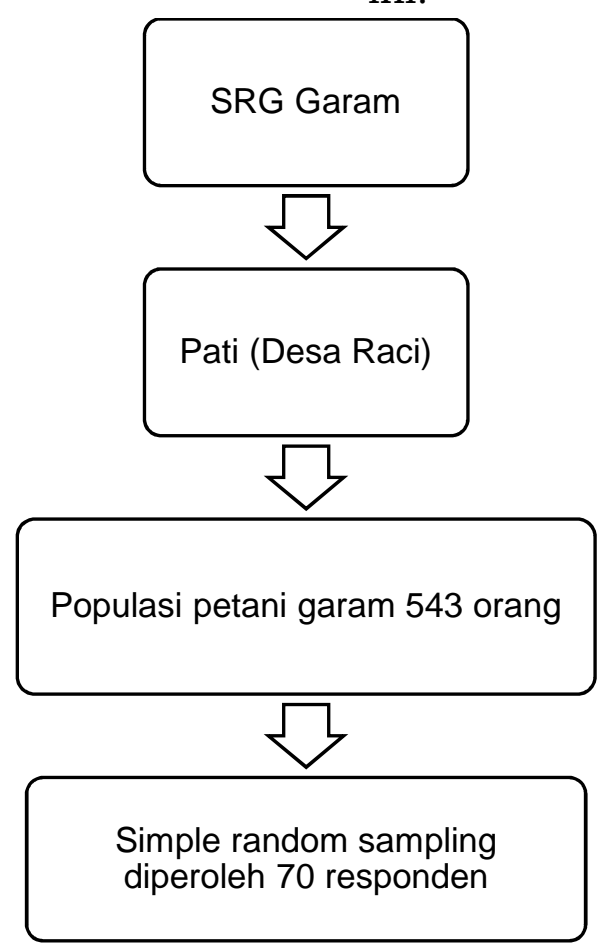

Gambar 1. Diagram Alur Metode Yang Dilaksanakan

\section{ANALISIS DATA}

Gambaran pelaksanaan SRG dianalisis dengan menggunakan metode deskriptif. Faktor-faktor yang mempengaruhi respon petani garam tentang SRG dianalisis dengan resgresi linear berganda menggunakan software EViews 9. Berikut adalah model regresi linear berganda yang digunakan:

$$
\begin{gathered}
\mathrm{Y}=\mathrm{a}+\beta 1 \mathrm{X} 1+\beta 2 \mathrm{X} 2+\beta 3 \mathrm{X} 3+\beta 4 \mathrm{X} 4+ \\
\beta 5 \mathrm{X} 5+\beta 6 \mathrm{X} 6+\mathrm{e}
\end{gathered}
$$


Keterangan:

$$
\begin{array}{ll}
\mathrm{a} & =\text { Konstanta } \\
\beta & =\text { Koefisien regresi } \\
\mathrm{Y} & =\text { Respon petani garam } \\
\mathrm{X} 1 & =\text { Umur (tahun) } \\
\mathrm{X} 2 & =\text { Tingkat pendidikan } \\
\mathrm{X} 3 & =\text { Luas lahan (Ha) } \\
\mathrm{X} 4 & =\text { Motivasi } \\
\mathrm{X} 5 & =\text { Persepsi } \\
\mathrm{X} 6 & =\text { Peran PPL } \\
\mathrm{e} & =\text { Error }
\end{array}
$$

Uji asumsi klasik adalah persyaratan statistik yang harus dipenuhi pada analisis linear berganda yang berbasis Ordinary Least Square (OLS) sehingga model yang dihasilkan memiliki varian minimum (Best Linear Unbiased Estimator). Uji asumsi klasik pada penelitian ini meliputi uji normalitas, uji heterokedastisitas, uji multikolinearitas, dan uji autokolerasi. Ketepatan (goodness of fit) model regresi linear berganda yang dihasilkan ditunjukkan dari nilai koefisien determinasi $\left(\mathrm{R}^{2}\right)$, hasil Uji $\mathrm{F}$ dan hasil Uji t.

Uji t adalah uji yang digunakan untuk menguji signifikansi hubungan antara variabel dependen (X) dan variabel independent $(\mathrm{Y})$ secara parsial atau bisa dikatakan bahwa uji t dapat menunjukkan seberapa jauh satu variabel independen $(\mathrm{Y})$ secara individual dalam menerangkan variasi-variasi variabel dependen (X). Taraf kepercayaan yang digunakan adalah $95 \%$ atau dengan nilai a sebesar 0,05. Hipotesis uji t, apabila: $\mathrm{H}_{0}: \mathrm{b}_{1}=\mathrm{O}$ (tidak ada pengaruh yang signifikan)

$\mathrm{H}_{1}: \quad \mathrm{b}_{1} \neq 0 \quad$ (ada pengaruh yang signifikan) Kriteria pengambilan keputusan:

$t_{\text {hit }}>t_{\text {tab }} \rightarrow$ berbeda secara signifikan ( $\mathrm{H}_{0}$ ditolak)

$t_{\text {hit }}<t_{\text {tab }} \rightarrow$ tidak berbeda secara signifikan ( $\mathrm{H}_{0}$ diterima) atau
Jika probabilitas $>0,05$ maka $\mathrm{H}_{0}$ ditolak.

Jika probabilitas $<0,05$ maka $\mathrm{H}_{0}$ diterima.

Uji $\mathrm{F}$ atau uji simultan adalah uji yang digunakan untuk menguji apakah variabel independent (Y) secara bersama-sama berpengaruh terhadap variabel dependen (X) dari suatu persamaan regresi dengan menggunakan hipotesis statistik. Taraf kepercayaan yang digunakan adalah $95 \%$ atau dengan nilai a sebesar 0,05. Hipotesis uji F, apabila: $\mathrm{H}_{0}: \mathrm{b}_{1}=0$ (tidak ada pengaruh yang signifikan)

$\mathrm{H}_{1}: \quad \mathrm{b}_{1} \neq \mathrm{O} \quad$ (ada pengaruh yang signifikan)

Kriteria pengambilan keputusan:

$\mathrm{F}_{\text {hit }}>\mathrm{F}_{\text {tab }} \rightarrow$ berbeda secara signifikansi ( $\mathrm{H}_{0}$ ditolak).

$\mathrm{F}_{\text {hit }}<\mathrm{F}_{\text {tab }} \rightarrow$ tidak berbeda secara signifikansi ( $\mathrm{H}_{0}$ diterima) atau

Jika probabilitas $>0,05$ maka $\mathrm{H}_{0}$ ditolak.

Jika probabilitas $<0,05$ maka $\mathrm{H}_{0}$ diterima.

\section{HASIL DAN PEMBAHASAN}

\section{Hasil Uji Instrument Penelitian}

Dari uji validitas dan reliabilitas untuk variabel motivasi (X4), persepsi (X5), dan peran PPL (X6) menunjukkan hasil yang signifikan. Pada uji validitas, pengambilan keputusan diambil dengan membandingkan nilai total skor $r$ hitung dengan nilai $r$ tabel. Uji validitas untuk variabel $\mathrm{Y}, \mathrm{X} 4, \mathrm{X}$, dan X6 menunjukkan bahwa seluruh pernyataan memenuhi syarat dimana nilai $r$ hitung (Pearson Correlation) lebih besar dari $r$ tabel 0,235 sehingga dapat disimpulkan bahwa setiap pernyataan pada variabel dinyatakan valid. Uji reliabilitas Cronbach Alpha dari keempat variabel yaitu Y, X3, X4, 
dan X5 menunjukkan nilai lebih dari 0,6 sehingga dapat disimpulkan bahwa pernyataan yang dibuat sudah reliabel.

\section{Alur Pelaksanaan SIstem Resi Gudang Di Desa Raci Kecamatan Batangan}

Dalam pelaksanaannya, Sistem Resi Gudang memiliki alur yang harus dilakukan sampai petani garam bisa menerima resi gudang yang dapat digunakan untuk melakukan pinjaman di bank. Pelaksanaan SRG di Desa Raci masih tergolong sangat rendah. Dari 70 responden petani garam, baru satu responden saja yang menggunakan SRG karena mereka belum terbiasa untuk menggunakan sistem tersebut dalam usaha mereka. Bagi petani garam yang ingin menyimpan garam di gudang dapat menghubungi pihak pengelola gudang, selanjutnya pengelola gudang akan melakukan pengecekan garam di lokasi. Adapun yang dicek adalah kadar $\mathrm{NaCl}$ pada garam. Garam yang dapat disimpan dalam gudang adalah garam industri dengan kadar $\mathrm{NaCl}$ sebesar 97\% dengan kandungan Sulfat $\left(\mathrm{SO}_{4}\right)$, Magnesium (Mg), Kalium (K), dan kotoran lainnya dalam jumlah yang kecil. Garam yang memenuhi syarat, selanjutnya dibawa ke gudang untuk ditimbang dan kembali dicek oleh Lembaga Penilaian Kesesuaian (LPK) untuk menerima asuransi garam yang diberikan oleh Asuransi Jasa Indonesia (Jasindo). Resi gudang akan diterbitkan oleh pengelola gudang namun sebelumnya pengelola gudang harus melakukan registrasi resi terlebih dahulu ke pusat registrasi dalam hal ini adalah Kliring Berjangka Indonesia (KBI). Setelah itu baru resi dapat diterima oleh petani garam. Resi gudang yang berupa lembaran kertas adalah bukti kepemilikan atas barang yang disimpan di dalam gudang yang diterbitkan oleh pengelola gudang (Pasal 1 ayat 2 UU Resi Gudang). Resi gudang berhak diterima oleh setiap pemilik barang yang menyimpan barang di dalam gudang. Resi gudang inilah yang nantinya dapat digunakan untuk penjaminan jika petani membutuhkan modal (Hariyani \& Serfianto, 2010). Setelah menerima resi, petani garam bisa datang ke bank yang sudah bekerja sama untuk kredit. Bank yang dimaksud dalam hal ini adalah Bank Rakyat Indonesia (BRI) dan Bank Jateng. Berikut adalah alur pemberian kredit resi gudang oleh pihak bank:

1. Petani garam mengajukan permohonan kredit ke bank dengan membawa resi gudang yang sudah diterima dari pengelola gudang.

2. Bank memproses permohonan kredit dengan melakukan prosedur sebagai berikut:

a. Melakukan survey barang yang disimpan ke gudang penyimpanan.

b. Melakukan verifikasi ke pusat registrasi untuk mengkonfirmasi bahwa resi gudang yang diajukan untuk pinjaman kredit belum dibebani hak jaminan apapun.

3. Pencatatan pembebanan hak jaminan yang dilakukan ke pusat registrasi kemudian pengikatan jaminan serta pencairan kredit.

4. Selama kredit berlangsung apabila harga komoditas sudah baik dan pemilik ingin menjual garamnya maka dapat langsung berhubungan dengan pedagang dan membuat kontrak jual beli garam. 
5. Setelah saling sepakat maka pembeli harus membayar garam melalui bank.

6. Bank membuat surat pengeluaran barang yang dibeli kepada pengelola gudang dengan persetujuan debitur.

Setelah menerima surat pengeluaran barang, pengelola gudang dapat mengeluarkan barang untuk dikirim kepada pembeli.

\section{Analisis Karakteristik Responden}

Karakteristik petani garam yang diteliti meliputi umur (X1), tingkat pendidikan (X2) dan luas lahan yang dikelola (X3) dapat dilihat pada tabel 1 -3 :

Tabel 2. Karakteristik Responden Berdasarkan Tingkat Umur

\begin{tabular}{ccc}
\hline Umur (Tahun) & Jumlah (orang) & Persentase (\%) \\
\hline $30-39$ & 4 & 5,71 \\
$40-49$ & 23 & 32,86 \\
$50-59$ & 30 & 42,86 \\
$60-69$ & 10 & 14,29 \\
$>70$ & 3 & 4,29 \\
\hline Jumlah & $\mathbf{7 0}$ & $\mathbf{1 0 0}$
\end{tabular}

Sumber: Olah Data Primer (diolah), 2018

Berdasarkan Tabel 2 seseorang. Kapasitas belajar menunjukkan bahwa jumlah seseorang berkembang lebih cepat responden paling banyak adalah pada pada usia 20 tahun dan akan semakin kelompok usia 50-59 tahun sebanyak berkurang saat menginjak usia 50 30 orang dengan persentase 41,86\% tahun dengan kata lain semakin muda dengan rata-rata umur responden umur penerima inovasi maka tingkat adalah 52 tahun. Secara ekonomis, pengambilan keputusan adopsinya usia dapat menunjukkan produktifitas akan lebih tinggi pula.

Tabel 3. Karakteristik Responden Berdasarkan Tingkat Pendidikan

\begin{tabular}{ccc}
\hline Tingkat Pendidikan & Jumlah (orang) & Persentase (\%) \\
\hline SD & 38 & 54,29 \\
SMP & 22 & 31,43 \\
SMA & 5 & 7,14 \\
D3 & 1 & 1,43 \\
S1 & 4 & 5,71 \\
\hline Jumlah & $\mathbf{7 0}$ & $\mathbf{1 0 0 , 0 0}$
\end{tabular}

Sumber: Olah Data Primer (diolah), 2018

Berdasarkan Tabel 3 jumlah responden paling banyak adalah pada tingkatan SD sebanyak 38 orang dengan persentase $54,29 \%$. Tingkat pendidikan dan pengetahuan seseorang akan dapat berpengaruh terhadap perilaku dan tindakan seseorang dalam pengambilan suatu keputusan dan sikap. Semakin tinggi tingkat pendidikan seseorang maka semakin cepat dalam proses penyerapan pengalaman baru. Persentase terbanyak yang diperoleh menunjukkan bahwa tingkat 
pendidikan petani garam masih tergolong rendah sehingga masih sulit dalam menerima inovasi.

Tabel 4. Karakteristik Responden Berdasarkan Luas Lahan Garapan

\begin{tabular}{ccc}
\hline Luas Lahan (Ha) & Jumlah (orang) & Persentase (\%) \\
\hline$<0,5$ & 13 & 18,57 \\
$0,6-2$ & 57 & 81,43 \\
\hline Jumlah & $\mathbf{7 0}$ & $\mathbf{1 0 0 , 0 0}$ \\
\hline
\end{tabular}

Sumber: Olah Data Primer (diolah), 2018

Berdasarkan Tabel 4. jumlah penguasaan lahan paling banyak adalah berkisar pada 0,6-2 ha yaitu sebanyak 57 orang dengan persentase $81,43 \%$ dengan rata-rata luas lahan responden adalah 1 ha. Luas lahan garapan berpengaruh terhadap produksi yang dihasilkan. Semakin luas lahan yang dikelola maka semakin besar pula pendapatan yang akan diterima. Dari hasil yang diperoleh dapat dikatakan bahwa luas lahan garapan petani garam dalam kategori sedang.

\section{Hasil Analisis Pengaruh Faktor Umur (X1), Tingkat Pendiidkan (X2), Luas Lahan (X3), Motivasi (X4), Persepsi (X5), Peran PPL (X6) Tentang Respon Pegaram (Y)}

Faktor-faktor yang diduga berpengaruh tentang respon petani garam meliputi umur (X1), tingkat pendidikan (X2), luas lahan (X3), motivasi (X4), persepsi (X5), dan peran PPL (X6). Persamaan regresi linear berganda yang diperoleh dari hasil analisis adalah:

$$
\begin{gathered}
\mathrm{Y}=5,98+0,015 \mathrm{X} 1+0,496 \mathrm{X} 2- \\
0,608 \mathrm{X} 3+0,123 \mathrm{X} 4+0,263 \mathrm{X} 5+ \\
0,27 \mathrm{X} 6 \mathrm{e} .
\end{gathered}
$$

Hasil analisis regresi linear berganda terhadap masing-masing variabel umur (X1), tingkat pendidikan (X2), luas lahan (X3), motivasi (X4), persepsi (X5), peran PPL (X6) terhadap respon petani garam (Y) disajikan dalam tabel dibawah ini:

Tabel 5. Pengaruh Faktor Umur (X1), Tingkat Pendidikan (X2), Luas Lahan (X3), Motivasi (X4), Persepsi (X5), dan Peran PPL (6) tentang Respon Petani garam (Y)

\begin{tabular}{cccccc}
\hline Var & Koef & Std. Error & t hit & Prob & Ket \\
\hline Kons & 5,98 & 2,323 & 2,574 & 0,012 & \\
X1 & 0,015 & 0,012 & 1,228 & 0,223 & TS \\
X2 & 0,496 & 0,148 & 3,35 & 0,001 & $\mathrm{~S}$ \\
X3 & $-0,608$ & 0,378 & $-1,605$ & 0,113 & TS \\
X4 & 0,123 & 0,113 & 1,079 & 0,284 & TS \\
X5 & 0,263 & 0,111 & 2,36 & 0,021 & $\mathrm{~S}$ \\
X6 & 0,27 & 0,083 & 3,249 & 0,001 & $\mathrm{~S}$ \\
\hline $\mathrm{R}^{2}$ & $=0,511$ & & & \\
$\mathrm{R}^{2}$ (adj) & $=0,465$ & & & \\
S.E. of regression & $=0,864$ & & & \\
F-hitung & $=10,998$ & & & \\
\hline
\end{tabular}




$\frac{\overline{\text { Probabilitas }}=0,000}{\text { Sumber: Olah Data Primer (diolah), } 2018}$

Keterangan: TS = Tidak Siginifikan .

$\mathrm{S} \quad=$ Signifikan.

Uji ketepatan model respon petani garam berdasarkan nilai koefisien determinasi $\left(\mathrm{R}^{2}\right)$ sebesar 0,511 menunjukkan $51,1 \%$ variasi respon petani garam dapat dijelaskan oleh variasi faktor umur, tingkat pendidikan, luas lahan, motivasi, persepsi dan peran PPL sedangkan sisanya $(48,9 \%)$ dijelaskan oleh faktor lain di luar model. Nilai Fhitung sebesar 10,998 lebih besar dari Ftabel 3,10 pada tingkat kesalahan $1 \%(\alpha=$ $0,01)$, berarti faktor umur (X1), tingkat pendidikan (X2), luas lahan (X3), motivasi (X4), persepsi (X5), peran PPL (X6) secara bersama-sama berpengaruh positif terhadap respon petani garam mengenai SRG dan berpengaruh negatif terhadap respon petani garam tentang SRG untuk variabel luas lahan (X3).

\section{Pengaruh Umur (X1) terhadap Respon Petani garam (Y)}

Dari hasil Tabel 5 dapat dilihat bahwa nilai koefisien regresi variabel umur (X1) sebesar 0,015 dengan tanda positif namun tidak signifikan pada tingkat kepercayaan 95\%. Pernyataan tersebut juga dapat dibuktikan pada hasil uji t dimana nilai thitung 1,228 < 1,671 tabel menunjukkan bahwa variabel umur tidak berpengaruh terhadap respon petani garam tentang SRG sehingga hal tersebut sesuai dengan pernyataan Kartasapoetra (1991) menyatakan bahwa petani yang berusia lebih dari 50 tahun sulit untuk menerima hal baru seperti SRG. Sesuai dengan hasil karakteristik respon yang menunjukkan bahwa petani garam dominan pada rentang usia 50 - 59 tahun sebanyak 41,86\% yang berarti bahwa usia tersebut tergolong usia yang sulit untuk menerima inovasi baru. Mereka cenderung menggunakan tradisi dalam berusaha tani yang sudah dijalani sejak lama. Petani garam di Desa Raci didominasi oleh petani usia tua karena banyak generasi muda yang lebih memilih untuk bekerja diluar kota. Menurut Novia (2011) petani dengan usia muda pada umumnya memiliki aspek konseptual yang lebih baik namun kurang dalam hal pengalaman dan ketrampilan, sedangkan petani yang sudah tua cenderung kurang dalam memahami inovasi baru namun pemahaman akan berusaha lebih baik.

\section{Pengaruh Tingkat Pendidikan (X2) terhadap Respon Petani garam (Y)}

Dari hasil Tabel 5 dapat dilihat bahwa nilai koefisien regresi variabel tingkat pendidikan (X2) sebesar 0,496 dengan tanda positif dan signifikan pada tingkat kepercayaan 95\%. Pernyataan tersebut juga dapat dibuktikan pada hasil uji $t$ dimana nilai thitung $3,35>1,671 t_{\text {tabel }}$ menunjukkan bahwa variabel tingkat pendidikan berpengaruh terhadap respon petani garam tentang SRG. Nilai koefisien regresi linear pada variabel tingkat pendidikan (X2) sebesar 0,496 sehingga dapat dikatakan bahwa dengan penambahan satu tingkat pendidikan akan meningkatkan persentase respon petani garam tentang SRG. 
Mardikanto (1993) mengatakan bahwa tingkat pendidikan seseorang mempengaruhi kapasitas belajar dikarenakan ada kegiatan tertentu yang memerlukan tingkat pengetahuan tertentu juga untuk dapat memahaminya. Sesuai dengan karakteristik responden pada Tabel 2 menunjukkan bahwa tingkat pendidikan petani garam di desa Raci masih didominasi oleh lulusan SD yaitu sebanyak 54,29\% sehingga petani garam masih mengalami kesulitan untuk menerima dan menerapkan inovasi dalam usaha garam mereka. Hal itu disebabkan oleh tradisi yang sudah mereka lakukan selama bertahun-tahun dan turun-temurun. Dari hal tersebut dapat disimpulkan bahwa semakin tinggi tingkat pendidikan seseorang maka akan semakin baik pula pengetahuan, ketrampilan, dan sikapnya dalam merespon pengalaman baru.

\section{Pengaruh Luas Lahan (X3) terhadap Respon Petani garam (Y)}

Dari hasil Tabel 5 dapat dilihat bahwa nilai koefisien regresi variabel luas lahan (X3) sebesar -0,608 dengan tanda negatif dan tidak signifikan pada tingkat kepercayaan 95\%. Pernyataan tersebut juga dapat dibuktikan pada hasil uji $\mathrm{t}$ dimana nilai $t_{\text {hitung }}-1,605<1,671 \quad t_{\text {tabel }}$ menunjukkan bahwa variabel luas lahan tidak berpengaruh terhadap respon petani garam tentang SRG.

Tabel 6. Luas Lahan Garapan

\begin{tabular}{ccc}
\hline Luas Lahan (Ha) & Jumlah (n) & Persentase (\%) \\
\hline$<0,5$ & 13 & 18,57 \\
$0,6-2$ & 57 & 81,43 \\
\hline Jumlah & $\mathbf{7 0}$ & $\mathbf{1 0 0}$ \\
\hline
\end{tabular}

Sumber: Olah Data Primer (diolah), 2018

Menurut Fhadoli (1990) luas garapan yang dimiliki petani garam di Desa Raci tergolong dalam katerogi lahan garapan sedang. Berbeda dengan pernyataan Soekartawi (1995) yang mengatakan bahwa ukuran kesuksesan usahatani salah satunya dicirikan dengan luas lahan yang berhubungan positif dengan inovasi pada pertanian. Hal ini disebabkan inovasi membutuhkan skala operasi dan sumberdaya ekonomi yang tinggi untuk keperluan adopsi inovasi baru tersebut. Selain itu penggunaan teknologi yang lebih baik diharapkan mampu menghasilkan manfaat ekonomi dari perluasan usahatani. Hal ini tidak terjadi pada penelitian petani garam di Desa Raci, luas lahan responden relatif homogen berada pada rentang 0,6-2 ha yaitu sebesar $81,43 \%$ sehingga respon mereka tentang SRG tidak siginifikan. Berbeda dengan penelitian Kurniawan (2009) dan Susanti (2013) yang menunjukkan bahwa luas lahan petani padi berpengaruh terhadap penerapan SRG. semakin luas lahan petani padi maka akan semakin banyak pula hasil gabah yang akan dipanen sedangkan untuk komoditas garam lahan hanya menjadi media untuk penjemuran saja. Luasan lahan tidak mempengaruhi karena hasil panen lebih bergantung pada bahan utama yang diolah yaitu air laut. 


\section{Pengaruh Motivasi (X4) terhadap Respon Petani Garam (Y)}

Dari hasil Tabel 5 dapat dilihat bahwa nilai koefisien regresi variabel motivasi (X4) sebesar 0,123 dengan tanda positif dan tidak signifikan pada tingkat kepercayaan 95\%. Pernyataan tersebut juga dapat dibuktikan pada hasil uji t dimana nilai thitung $1,079<$ 1,671 tabel menunjukkan bahwa variabel motivasi tidak berpengaruh terhadap respon petani garam tentang
SRG. Nilai koefisien regresi linear pada variabel motivasi sebesar 0,123. Berbeda dengan penelitian Nugraha (2014) yang menyatakan bahwa motivasi mempengaruhi respon petani garam tentang SRG sehingga apabila semakin tinggi tingkat motivasi petani garam dalam keinginannya mengikuti SRG maka semakin tinggi juga petani garam akan merespon keberadaan SRG.

Tabel 7. Penggolongan Kategori Variabel Motivasi (X4)

\begin{tabular}{lcc}
\hline \multicolumn{1}{c}{ Kategori } & Responden (Orang) & Persentase (\%) \\
\hline Rendah (skor 4 - 8) & 0 & 0,00 \\
Sedang (skor 9-15) & 16 & 22,85 \\
Tinggi (skor 16 - 20) & 54 & 77,14 \\
\hline Jumlah & $\mathbf{7 0}$ & $\mathbf{1 0 0 , 0 0}$ \\
\hline
\end{tabular}

Sumber: Olah Data Primer (diolah), 2018

Berbeda dengan hasil uji regresi, pada Tabel 7 sebanyak 77,14\% responden memiliki motivasi tinggi dalam merespon keberadaan SRG namun pada hasil uji memperlihatkan bahwa motivasi tidak mempengaruhi respon petani garam tentang SRG. Pada kenyataannya semenjak diresmikannya SRG baru satu petani garam saja yang menggunakan SRG sehingga banyak petani garam lain yang belum melihat manfaat yang diperoleh setelah menggunakan SRG.

\section{Pengaruh Persepsi (X5) terhadap Respon Petani garam (Y)}

Dari hasil Tabel 5 dapat dilihat bahwa nilai koefisien regresi variabel persepsi (X5) sebesar 0,263 dengan tanda positif dan signifikan dengan taraf kepercayaan 95\%. Pernyataan tersebut juga dapat dibuktikan pada hasil uji $t_{\text {hitung }} 2,36>1,671 \mathrm{t}_{\text {tabel }}$ menunjukkan bahwa variabel persepsi berpengaruh nyata terhadap respon petani garam tentang SRG. Nilai koefisien regresi pada variabel persepsi sebesar 0,263 sehingga dengan meningkatnya persepsi petani garam akan meningkatkan pula respon petani garam tentang SRG. Hasil penelitian ini sesuai dengan penelitian Wijayanti (2015) yang menjelaskan bahwa semakin baik persepsi petani maka semakin tinggi pula respon petani terhadap inovasi budidaya.

\section{Pengaruh Peran PPL (X6) terhadap Respon Petani garam (Y)}

Dari hasil Tabel 5 dapat dilihat bahwa koefisien regresi variabel peran PPL (X6) sebesar 0,27 dengan tanda positif dan signifikan pada tingkat kepercayaan 95\%. Pernyataan tersebut juga dapat dibuktikan pada hasil uji t dimana nilai thitung 3,249 > 1,671 tabel menunjukkan bahwa variabel peran PPL berpengaruh terhadap respon petani garam tentang 
SRG. Nilai koefisien regresi pada variabel peran PPL sebesar 0,27 sehingga dengan penambahan PPL atau penyuluhan dari PPL mengenai SRG akan meningkatkan persentase respon petani garam tentang SRG. Hasil penelitian ini sesuai dengan penelitian Kurniawan (2009) bahwa semakin aktif PPL memberikan penyuluhan maka akan meningkatkan juga keikutsertaan petani untuk mengikuti SRG. Dalam hal ini PPL memiliki peran penting untuk membimbing petani garam supaya bisa menerima inovasi yang dibuat demi menguntungkan produsen garam. Penyuluh bertugas untuk menyampaikan informasi mengenai SRG, meningkatkan pengetahuan, sikap, dan ketrampilan petani garam.

\section{KESIMPULAN DAN SARAN}

\section{Kesimpulan}

1. Pelaksanaan SRG di Desa Raci masih tergolong sangat rendah. Dari 70 responden petani garam, baru satu responden saja yang menggunakan SRG karena mereka belum terbiasa untuk menggunakan sistem tersebut dalam usaha mereka.

2. Faktor-faktor yang mempengaruhi respon petani garam tentang SRG adalah tingkat pendidikan, persepsi mengenai SRG, dan peran PPL sedangkan faktor yang tidak berpengaruh adalah umur, luas lahan, dan motivasi.

\section{Saran}

1. Melihat dari hasil yang menunjukkan bahwa umur, luas lahan, dan motivasi yang tidak berpengaruh terhadap respon petani garam tentang SRG maka diharapkan agar PPL lebih bisa memotivasi petani garam yang didominansi oleh petani garam usia tua supaya mau menggunakan SRG dalam usaha garam mereka sehingga dengan diadakannya SRG di Desa Raci bisa dimanfaatkan dengan optimal.

2. Keterlibatan pemerintah daerah sangat diperlukan dalam hal sosialisasi kepada petani garam mengenai pentingnya mengikuti SRG terutama untuk petani garam di wilayah Kabupaten Pati dikarenakan gudang masih tergolong baru dan belum banyak petani garam yang tertarik menggunakan SRG.

\section{DAFTAR PUSTAKA}

Fhadoli, H. 1990. Ilmu Usahatani. Jurusan Ilmu-ilmu Sosial Ekonomi Pertania. Institut Pertanian Bogor. Bogor.

Hariyani I. \& Serfianto R. 2010. Resi Gudang Sebagai Jaminan Kredit \& Alat Perdagangan. Sinar Grafika. Jakarta.

Kartasapoetra, A. G. 1991. Teknologi Penyuluhan Pertanian. Bumi Aksara. Jakarta.

Kurniawan, D. 2009. Faktor-faktor Yang Mempengaruhi Penerapan Sistem Resi Gudang Oleh Petani Padi Di Kecamatan Palasah, Kabupaten Majalengka, jawa Barat. Institut Pertanian Bogor. Bogor.

Mardikanto, T. 1993. Penyuluhan Pembangunan Kehutanan. UNS Press. Surakarta.

Novia, R.A. 2011. Respon Petani Terhadap Kegiatan Sekolah Lapang Pengelolaan Tanaman 
Terpadu. Jurnal Ilmu - Ilmu

Pertanian. Vol 7. No. $2: 48-60$.

Nugraha, P. A. 2014. Respon Petani Terhadap Sistem Resi Gudang di Kabupaten Bantul. Universitas Gajah Mada. Yogyakarta.

Soekartawi. 1995. Analisis Usahatani. Jakarta. UI Press.

Sugiyono. 2006. Metode Penelitian Kuantitatif, Kualitatif dan R\&D. Alfabeta, Bandung.

Sugiyono. 2011. Metode Penelitian Kuantitatif, Kualitatif dan R\&D. Alfabeta, Bandung.

Wijayanti A., Subejo, dan Haryoso. 2015. Respons Petani Terhadap Inovasi Budidaya dan Pemanfaatan Sorgum di Kecamatan Srandakan Kabupaten Bantul. Jurnal Agro Ekonomi Vol. 26/No.2 